\title{
Motrivivancia
}

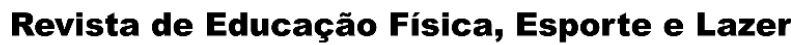

LaboMídia

\section{Perspectivas sobre as mulheres no campo do futebol/futsal feminino: o que as pesquisas nos periódicos nacionais evidenciam}

\section{RESUMO}

Este estudo se propôs a analisar a produção acadêmica brasileira no campo da Educação Física acerca do futebol/futsal feminino afins de identificar quais os indícios científicos os estudos em questão apresentam. A pesquisa possui caráter qualitativo, já que opera uma Revisão Sistemática da Literatura (RSL). Como critério para a seleção dos periódicos, foram priorizados aqueles voltados para a área de Educação Física, com estratificação B e A segundo a avaliação da CAPES (Qualis) e publicados entre 2015 e 2020. No transcurso da pesquisa, doze artigos de seis revistas, na perspetiva quanti-qualitativa, foram analisados. Para proceder com a análise, foram criadas duas categorias: (i) aspectos históricos, sociais e culturais; (ii) performance e alto rendimento. $\mathrm{O}$ campo de pesquisa sobre futebol/futsal feminino destaca discussões sobre gênero, incentivos e preconceitos.

PALAVRAS-CHAVE: Futebol feminino; Estigma de gênero; Profissionalização esportiva
José Ricardo Lopes Ferreira Mestre em Educação Estácio de Sá, Faculdade de Alagoas, Maceió, Brasil r2ferreira.edf@gmail.com (ㄴ https://orcid.org/0000-0001-7921-8413

Lucas Xavier de Melo Graduado em Educação Física Estácio de Sá, Faculdade de Alagoas, Maceió, Brasil lucas-missao2010@hotmail.com 느 https://orcid.org/0000-0003-1843-8353

Hadonay Jonys Souza Lima

Graduado em Educação Física Estácio de Sá, Faculdade de Alagoas, Maceió, Brasil hadonay ionys@hotmail.com Dhttps://orcid.org/0000-0003-0942-6385

Robson Arthur Moura Lima Graduado em Educação Física Estácio de Sá, Faculdade de Alagoas, Maceió, Brasil robsonarthur123@gmail.com 는 https://orcid.org/0000-0002-7985-3465

Lucas Fellype Buarque De Melo Graduado em Educação Física Estácio de Sá, Faculdade de Alagoas, Maceió, Brasil 1fbmelo@outlook.com Dhttps://orcid.org/0000-0001-6051-8205 


\title{
Perspectives on women in the field of women's football / futsal: what research in national
} journals shows.

\begin{abstract}
This study aimed to analyze the Brazilian academic production in the field of Physical Education about women's football / futsal, in order to identify what scientific evidence the studies in question present. A qualitative approach methodology was adopted, such as Systematic Literature Review (SLR), in which searches were concentrated on magazines focused on the area of Physical Education with stratification of B and A according to Qualis (CAPES) in the period from 2015 to 2020. In the course of the research, twelve articles from six journals, from a quanti-qualitative perspective, were analyzed. To proceed with the analysis, two categories were created: (i) historical, social and cultural aspects; (ii) performance and high performance. The women's football / futsal research field highlights discussions about gender, incentives and prejudices.
\end{abstract}

KEYWORDS: Women's football; Gender stigma; Sports professionalization

Perspectivas sobre las mujeres en el campo del fútbol femenino / fútbol sala: lo que muestra la investigación en revistas nacionales.

\section{RESUMEN}

Este estudio tuvo como objetivo analizar la producción académica brasileña en el campo de la Educación Física sobre fútbol / fútbol sala femenino, con el fin de identificar qué evidencia científica presentan los estudios en cuestión. La investigación tiene un carácter cualitativo, ya que opera una Revisión Sistemática de Literatura (RSL). Como criterio para la selección de revistas, se dio prioridad a aquellos enfocados en el área de Educación Física, con estratificación $\mathrm{B}$ y A según la evaluación CAPES (Qualis) y publicados entre 2015 y 2020. En el curso de la investigación, doce artículos de seis revistas, desde una perspectiva cuantitativa, se analizaron. Para proceder con el análisis, se crearon dos categorías: (i) aspectos históricos, sociales y culturales; (ii) rendimiento y alto rendimiento. El campo de investigación de fútbol femenino / fútbol sala destaca las discusiones sobre género, incentivos y prejuicios.

PALABRAS-CLAVE: Educación física en la escuela; Enseñanza fundamental; Construcción curricular 


\section{INTRODUÇÃO}

Em 1921, ocorreu a primeira partida de futebol feminino no Brasil, na cidade de São Paulo (MOREL; SALES, 2006). Com o decorrer de todos esses anos, há quem pense que, atualmente, não há mais preconceitos ou dificuldades. Infelizmente, engana-se quem pensa assim. Desde o início até hoje, as mulheres têm lutado arduamente para poder jogar futebol. Em 1964, o Conselho Nacional de Desportos (CND) chegou a proibir a prática do futebol feminino no Brasil. De acordo com, Goellner (2005), neste período, imperava a identidade do corpo materno e da delicadeza feminina, visto como um bem social, motivando o cerceamento da participação das mulheres em práticas esportivas consideradas violentas.

Além disso, outros fatores históricos conforme Morel e Salles (2006), representaram entraves para o desenvolvimento do futebol feminino, como: a noção de que a prática do futebol era nociva para mulheres, sendo assim marginalizada; a falta de estudos acerca do desenvolvimento fisiológico feminino dera origem a preconceitos; os valores sexistas; conflitos com os interesses da mídia. O que culminou no enfraquecimento da prática esportiva do pelas mulheres.

Goellner (2005), afirma que no início da década de 1980, o futebol feminino ganhou investimentos das mídias a partir do apelo a beleza e erotização dos corpos das jogadoras na busca de atrair o público aos estádios. Investimento eu não apresentei o retorno esperado, gerando um desinvestimento no futebol feminino.

A década de 1990, foi marcada por uma crescente adesão das mulheres pelo futebol, no entanto, Morel e Salles (2006), relatam que não foi o bastante para despertar interesse na mídia, um dos meios responsáveis pela expansão das manifestações esportivas. Em linhas gerais, pode-se observar que a expansão da modalidade depende dos mesmos elementos que alavancaram o futebol masculino, no entanto, foi tolhida diante dos fatores históricos apresentados.

Segundo Pires (2017), as mulheres se uniram em um movimento de resistência na busca de afirmar sua posição na sociedade superando esses tipos de preconceito Apesar de reconhecer os avanços, é inegável que há, em várias modalidades esportivas, uma resistência à presença feminina (D'AVILLA e SOUZA apud CORRÊA et al., 2015). O futebol, com certeza, é uma dessas modalidades, pois, quando se fala sobre o futebol feminino no Brasil, as histórias, em sua maioria envolvem preconceito e dificuldade.

Franzini (2005), atribui esse preconceito ao pensamento, imposto pela sociedade, de que futebol é coisa para homem. A partir dessa imposição, são criados padrões estéticos para o esporte e, por meio de uma ditadura, o futebol é relacionado como um esporte exclusivamente masculino. É 
por isso que, segundo Corrêa, Silva e Masullo (2015), as mulheres decididas a jogar futebol precisam estar preparadas para enfrentar as inúmeras barreiras consequentes do preconceito e das discriminações.

Cientes das barreiras e impasses enfrentados pelas mulheres em busca da profissionalização nos esportes, sobretudo no futebol/futsal. Diante disso, surge-nos a inquietação de identificar como o campo científico da Educação Física tem estudado tal fenômeno, o que nos levou a seguinte problemática norteadora deste estudo: o que as investigações cientificas apresentam como indícios ou evidências em relação às mulheres no futebol/futsal feminino?

O objetivo principal foi analisar, de forma abrangente e sistemática, a produção acadêmica brasileira sobre a temática acima mencionada, a fim de identificar qual o olhar científico para o fenômeno do futebol feminino e quais são as principais evidências produzidas nas pesquisas na área da Educação Física. Para tanto, os artigos científicos publicados nos periódicos da área de Educação Física foram a fonte primária deste estudo.

Deste modo a metodologia empregada foi a da pesquisa de abordagem bibliográfica do tipo Revisão Sistemática da Literatura. Com base em uma perspectiva quanti-qualitativa, foi analisada a produção científica produzida sobre um fenômeno, a fim de colocar o autor de frente ao que já foi escrito de forma precisa (MARCONI; LAKATOS, 2011).

Para delimitar o campo de pesquisa bibliográfica recorreu-se ao sistema de estratificação Qualis da Coordenação de Aperfeiçoamento Pessoal de Nível Superior (CAPES). As revistas foram selecionadas a partir de critérios de inclusão e exclusão determinados no protocolo da RSL. Desta forma, foram analisadas sete revistas científicas especializadas na área de Educação Física, em língua portuguesa, com avaliação A e B segundo os requisitos do Qualis da CAPES. Após a definição dos periódicos foi realizada uma busca manual em cada número publicado e após aplicados os critérios de inclusão e exclusão, foram analisadas doze publicações.

Frente a esses apontamentos, este artigo foi organizado em três partes. A primeira delas trata sobre a estruturação do protocolo da pesquisa e o processo de seleção dos periódicos estudos bem como dos estudos a serem analisados. A segunda parte apresenta uma análise quantitativa em que foram mapeadas as frequências das publicações sobre esporte feminino nos periódicos selecionados, a quantidade de publicações por anos e as instituições participantes das pesquisas. E por fim, na terceira parte é apresentada uma síntese qualitativa sobre os estudos em busca de conhecer quais são as perspectivas e evidências apresentadas pelos estudos selecionados discutidos a partir das temáticas: (i) aspectos históricos, sociais e culturais; e (ii) performance e alto rendimento. 


\section{PERCURSO METODOLÓGICO}

Este estudo foi realizado através de uma revisão sistemática da literatura, com o objetivo de identificar e analisar as abordagens das pesquisas, reunidas nos periódicos nacionais da área de Educação Física, sobre o futebol e o futsal feminino. A base de dados utilizada, neste trabalho, foi o sistema Qualis-Capes, que classifica os periódicos por área de conhecimento.

O estudo se dá a partir de uma perspectiva quanti-qualitativa e operou um levantamento da produção científica acerca do futebol feminino. A finalidade desse processo é colocar o autor de frente ao que já foi escrito acerca do referido fenômeno (MARCONI; LAKATOS, 2011).

A princípio, foi feita uma busca, nas revistas acima mencionadas, a fim de encontrar estudos de revisão sistemática de literatura ou estado da arte que possuíssem enfoques voltados ao estudo das mulheres no futebol/futsal. Para tanto, foi realizado um levantamento nas plataformas Sciello, Scoppus e Periódicos CAPES. A partir dessa procura, evidenciamos a ausência de estudos com este enfoque, o que justifica o desenvolvimento desta pesquisa. A próxima etapa consistiu em definir o protocolo para a pesquisa documental composta de cinco etapas.

Quadro 1 - Protocolo da Revisão Sistemática de Literatura

\begin{tabular}{|c|c|}
\hline Etapa & Descrição \\
\hline I & Identificação dos periódicos investigados; \\
\hline II & Definição das perguntas que a RSL pretendeu responder; \\
\hline III & Definição dos strings de busca; \\
\hline IV & Busca manual de acordo com os critérios de inclusão e exclusão selecionados; \\
\hline V & Leitura dos textos selecionados; \\
\hline VI & Sistematização e análise dos estudos. \\
\hline
\end{tabular}

Fonte: os autores (2020).

Para definir o campo de busca dos artigos, os periódicos investigados neste estudo, foram definidos com base o sistema de avaliação Qualis-Capes disponível na Plataforma Sucupira, que os classifica com base em critérios pré-determinados em uma estratificação que vai de C até A1. A fonte de busca foi a estratificação referente ao quadriênio (2013-2016) no campo acadêmico científico da Educação Física. Para tal, foram definidos os seguintes critérios: (i) possuir estratificação B2, B1, A2 e A1 (Qualis-Capes); (ii) ter origem nacional; (iii) ser editorado em língua portuguesa; (iv) possuir todos os números disponíveis em sua plataforma digital; (v) possuir como escopo de divulgação científica o campo acadêmico da Educação Física. 
A segunda etapa se configurou na definição das perguntas que surgiram a partir do objetivo principal deste estudo:

Q1: Quais indícios e evidências as pesquisas apresentam em relação aos jogos digitais e a Educação Física Escolar?

Q1: Qual a frequência relativa das publicações?

Q3: De quais instituições foram originadas as pesquisas?

O passo seguinte foi a busca pelas publicações, nas revistas "Pensar a Prática", "Motrivivência", "Revista Brasileira de Ciências do Esporte (RBCE)", "Revista Brasileira de Ciência e Movimento", "Licere" e "Movimento e Revista da Educação Física". Para tanto, a busca ocorreu de forma manual a partir da visita em todos os números no recorte temporal entre $2015 \mathrm{e}$ 2020, incluindo números suplementares e dossiês a partir dos termos descritores: "futebol feminino"; "futsal feminino"; "mulheres no futebol"; e "mulheres no futsal". Nessa etapa, foram selecionados 12 artigos.

A seleção dos artigos foi realizada com base na leitura dos títulos, segundo os seguintes critérios: (i) ser um artigo original ou de ensaio; (ii) ser publicado após o ano de 2015 e (iii) ser publicado em língua portuguesa. Foram excluídos os artigos de revisão sistemática de literatura ou estado da arte. Após esta etapa, foram selecionados os 12 artigos.

Em seguida, ocorreu a leitura e a categorização dos estudos selecionados na etapa anterior. Os artigos foram agrupados em categorias criadas a partir do objetivo de cada pesquisa. Posteriormente, foram analisados através da análise interpretativa e sistematizados na seção a seguir. Essa etapa representa a quarta fase da RSL.

\section{ANÁLISE DOS RESULTADOS}

$\mathrm{Na}$ perspectiva quantitativa desta revisão sistemática de literatura, foram mapeadas as frequências das publicações sobre esporte feminino nos periódicos selecionados e as instituições participantes das pesquisas. Desta forma, foi possível compreender, amplamente, como o fenômeno do futebol feminino vem sendo estudado.

Primeiramente, para compreender de que modo foram produzidas estas pesquisas, mapeamos as Instituições responsáveis pelo desenvolvimento dos estudos, como forma de identificar os principais centros de pesquisa. A tabela a seguir foi elaborada considerando as 
instituições às quais estão vinculados os autores presentes nos artigos. É válido ressaltar que alguns artigos analisados contaram com mais Instituições envolvidas na estruturação do estudo.

Tabela 01 - Instituições responsáveis pelas pesquisas em futebol feminino

\begin{tabular}{|l|c|}
\hline Instituições & Produções \\
\hline UFPR & 3 \\
\hline UNIVASF & 2 \\
\hline UFRGS/UEL/UEM/UFC/UNICAMP/UFES/USP/UnB/Outras & 1 \\
\hline
\end{tabular}

Fonte: os autores - dados da pesquisa (2020).

Os dados acima sugerem que a Universidade Federal do Paraná (UFPR) foi responsável por $25 \%$ da produção acadêmica sobre futebol/futsal feminino, a partir do desenvolvimento de três estudos. Os estudos são voltados para o campo sócio-histórico e fazem resgastes históricos sobre o futebol feminino, bem como problematizam o preconceito e os estigmas de gênero que envolvem a profissão.

Os dados, ainda sugerem que a segunda instituição com maior número de estudos sobre o futebol/futsal feminino é a Universidade Federal do Vale do São Francisco (UNIVASF). Os trabalhos se concentram em duas áreas, quais sejam: o campo sócio-histórico - discutindo as vertentes que envolvem o futebol e a feminilidade - e o campo da fisiologia, com um estudo comparativo entre atletas universitárias de futebol feminino. As demais instituições apresentaram apenas um estudo relacionado ao futebol feminino.

Ainda em relação à abordagem quantitativa deste estudo, foi mapeada a frequência de publicações de artigos que estudaram o fenômeno do futebol feminino. Foi possível, então, identificar quais periódicos trabalham na popularização das referidas pesquisas.

Tabela 2- Pesquisas por periódico

\begin{tabular}{|l|c|}
\hline Periódico & Produções \\
\hline Pensar a Prática & 3 \\
\hline Motrivivência & 3 \\
\hline Revista Brasileira de Ciências do Esporte & 1 \\
\hline Revista Movimento & 1 \\
\hline Journal of Physical Education & 2 \\
\hline Revista Brasileira de Ciência e Movimento & 1 \\
\hline Licere & 1 \\
\hline Total & 12 \\
\hline
\end{tabular}

Fonte: os autores - dados da pesquisa (2020).

No campo da divulgação sobre os estudos que envolvem o futebol/futsal, destacam-se as revistas "Pensar a Prática" e a "Motrivivência". A primeira é editada pela Universidade Federal de Goiás (UFG) e possui estratificação B2, segundo os critérios de qualificação do Qualis Capes, com 
publicações a head print. A revista Motrivivência, por sua vez, é editada pela Universidade Federal de Santa Catarina e possui estratificação B1, segundo os mesmos critérios supracitados, com publicações trimestrais.

O periódico "Journal of Physical Education" apresentou duas pesquisas na proposta pesquisada. Esse periódico é editado pela Universidade Estadual de Maringá. Os demais periódicos tiveram apenas uma publicação sobre futebol no recorte temporal de cinco anos.

\subsection{Futebol/Futsal Feminino: perspectivas e evidências}

Após a análise quantitativa e a leitura, os artigos foram sistematizados em categorias para a análise qualitativa. A abordagem qualitativa foi realizada com o intuito de conhecer as perspectivas e evidências. Com base nos objetivos dos estudos, foram criadas duas categorias: (i) aspectos históricos, sociais e culturais e (ii) performance e alto rendimento.

\section{Aspectos históricos, sociais e culturais}

Nesta categoria, reunimos estudos que discutem as relações das mulheres com o futebol/futsal a partir das perspectivas histórica, social e cultural. Foram encontrados oito estudos com focos em representação, estigma de gênero, futebol amador, identidade e interações sociais.

Myskiw (2016), desenvolveu um ensaio etnográfico sobre as relações de gênero no universo das práticas esportivas, especialmente o futebol. O autor dá ênfase às imersões e tensões, relativas às posições e engajamentos no circuito de várzea, consequentes das sociabilidades entre grupos com pessoas do mesmo gênero e grupos com diversidade de gênero.

Também na discussão de gênero, Guirra e Almeida (2015) analisaram qual a percepção de jogadores de futebol a respeito das mulheres praticantes do mesmo esporte. Os estudos indicaram a existência de grande preconceito por parte da sociedade em relação às mulheres que praticam futebol. Também ficou evidente a falta de incentivo da mídia e das entidades governamentais em relação à tal prática.

Souza, Caparro e Silva (2017), identificaram como se posicionam atletas de futebol feminino, com longa vivência na modalidade, cujas trajetórias rompem com alguns pressupostos das normas de gênero. O estudo evidenciou as pressões sofridas por elas para a adequação aos padrões de gênero e exemplificou com casos de preconceito em relação às mulheres praticantes de futebol. 
Chan-Vianna e Moura (2017) pesquisaram as interações sociais que constroem novas expressões de feminilidade. O estudo aponta que as tensões sociais e as representações existentes no cenário do futebol feminino no Brasil constituem, por meio do futebol, uma ação coletiva desviante da norma de feminilidade.

No campo da profissionalização, Souza e Martins (2018)descrevem o perfil das atletas no contexto do futsal feminino e analisam a relação entre o perfil socioeconômico, a formação esportiva e a carreira esportiva. Segundo a investigação das autoras, o perfil das atletas é formado por mulheres de baixa renda. Nesse sentido, o trabalho apontou que, para as jogadoras, a carreira no futsal constitui um paradoxo, pois não se trata de um projeto de vida em si, mas de uma fonte de acesso a outros projetos, ou seja, através do futsal, elas podem almejar possibilidades de ascensão social. O futsal, então, aparece como um caminho capaz de viabilizar uma mudança social para as atletas.

No âmbito histórico, Salvani e Marchi Júnior (2016) apresentam a história do futebol feminino, contada pela revista Placar, com um recorte temporal de 30 anos (1980 a 2010). Os resultados foram divididos em três partes: a partir das décadas de 1980, 1990 e 2000. Na década de 1980 a 1990, a revista se esforçou para apresentar jogadoras em ações ou poses que lembrem as normativas de gênero.

A década de 1990 a 2000 é marcada por eventos internacionais e pela dicotomia na veiculação de mulheres futebolistas e modelos que jogam futebol. Já entre 2000 e 2010, destacam-se os bons eventos nacionais e internacionais e, além disso, os anseios que envolvem a profissionalização do futebol feminino (SALVANI; MARCHI JÚNIOR, 2016).

No campo midiático,Souza, Mendes e Jensen (2017) pesquisaram sobre o reduzido número de literaturas sobre o futebol, refletindo sobre o domínio masculino perpetuado nessa esfera. Nos poucos textos encontrados, quando as autoras não se desculpavam por estar escrevendo sobre essa temática, se afastavam de desenvolver análises técnicas.

Tiesler (2016), por fim, estudou a mobilidade internacional de jogadoras de futebol feminino. A autora busca, em seu artigo, discutir uma categoria capaz de abarcar o deslocamento de uma jogadora transnacional cuja experiência se dá em diferentes países e contextos socioeconômicos. 


\section{Performance e alto rendimento}

Esta categoria foi composta por quatro estudos que investigam a performance e o rendimento de jogadoras profissionais, semiprofissionais e amadoras no futebol/futsal. Os estudos versam sobre treinos táticos e lesões; características morfológicas e fisiológicas; aspectos técnicos e táticos.

Cosvosk et al. (2019), comparam os sintomas de Burnout de atletas universitárias de futebol feminino com a região geográfica, a ocorrência de lesões e a frequência de treinos físicos e táticos. A pesquisa aponta que o volume de treinamentos físicos e táticos parece ser um fator interveniente na exaustão física e emocional das atletas de futebol feminino universitário.

No âmbito do futsal feminino de alto rendimento, Queiroga et al. (2018), fizeram um estudo comparativo das características morfológicas de atletas titulares e reservas de uma determinada equipe. O estudo relata que tanto a composição corporal quanto a experiência esportiva são atribuídas ao desempenho. Os resultados sugerem, ainda, que as diferenças evidenciadas são capazes de contribuir para a tomada de decisão do treinador no momento de fazer a escalação do time titular.

No campo da fisiologia, Kassiano et al. (2019), desenvolveram uma pesquisa para testar se há diferença nas respostas fisiológicas e neuromusculares de atletas de futsal feminino em um jogo amistoso. O estudo sugere que, embora exista um aumento no lactato, esse não é suficiente para comprometer o desempenho das jogadoras durante e logo após a partida.

A partir de uma abordagem tática, Barreira (2018) analisou a vantagem, em campeonatos de futebol feminino, de jogar em casa. O estudo conclui que existe uma vantagem de jogar em casa no futebol feminino e esse fenômeno pode ser explicado por alguns fatores, tais como: a presença da torcida, o "efeito viagem", a familiaridade com o campo, o viés dos árbitros e fatores psicológicos.

Em linhas gerais, apesar dos avanços que envolvem o futebol feminino nos últimos anos, observa-se que a produção analisada nesta categoria, ainda se apresenta tímida quando comparada as discussões sócio-históricas. Desta forma, alguns elementos históricos auxiliam na compreensão da pouca produção científica sobre elementos táticos, técnico e físiológicos sobre o futebol feminino.

O estudo Morel e Sales (2007), e evidencia fatores históricos que influenciaram para a construção deste cenário, como por exemplo, a noção de que a prática do futebol era nociva para a saúde da mulher. Para os autores, a construção histórica de um corpo feminino voltado para maternidade ou delicadeza, fortemente influenciado por valores sexistas, que perpetuaram e contribuem para a desigualdade de gênero no esporte. 
Para Goellner (2005), ainda se apresenta precária a estruturação do futebol feminino no país, uma vez que o calendário de campeonatos se apresenta instável, os clubes não se interessam em contratar as atletas, e existe a ausência de políticas públicas e privadas que influenciem a participação no esporte. Para além disso, a autora enfatiza a influência da mídia esportiva que confere pouco espaço ao futebol feminino, concentrando as críticas ao comportamento das jogadoras e a sua imagem, em detrimento aos seus talentos esportivo.

\section{CONSIDERAÇÕES FINAIS}

Este estudo se propôs a analisar a produção, nos periódicos nacionais do campo de educação física, acerca do fenômeno do futebol feminino. Para delimitar o campo de pesquisa, foram selecionados, segundo critérios pré-determinados, 6 periódicos. O recorte temporal compreendeu os anos de 2015 a 2020 e foram identificados doze artigos científicos, como ensaios e artigos originais, os quais foram analisados de formas quantitativas e qualitativas. A analise destes estudos resultou em algumas considerações.

Primeiramente, no campo quantitativo, evidenciamos que a UFPR e a UNIVASF se destacam, na produção sobre futebol/futsal feminino, com cinco publicações, sendo três e duas, respectivamente. Em relação aos periódicos, as revistas "Pensar a Prática" e "Motrivivência" possuem 50\% das publicações no campo estudado. O que sugere um esforço conjunto na produção e divulgação de tais temáticas

Em relação à análise qualitativa, foi possível observar a concentração dos estudos em duas categorias distintas. A primeira diz respeito aos aspectos históricos, sociais e culturais e, já nessa categoria, foi encontrada uma diversidade de estudos que problematizam os estigmas de gênero, as dificuldades da profisssionalização de mulheres no futebol e a hegemonia do sexo masculino nas áreas que envolvem o futebol. A segunda refere-se às discussões acerca da ausência de incentivos das mídias e dos órgãos governamentais.

Esses dados evidenciam que, apesar do destaque dado ao futebol feminino nos últimos anos, ainda há inúmeras barreiras, físicas e sociais, que dificultam o desenvolvimento dessa modalidade, uma vez que implicam o desestimulo da sua prática e a profissionalização.

No campo da performance e do alto rendimento, os estudos são escassos quando comparados a outros esportes. Evidenciamos, no entanto, a existência de um esforço em estudar sobre os aspectos morfológicos,fisiológicos, fatores psicológicos e lesões no futebol profissional, semi profissional e amador.A escassez destes estudos pode ser explicada por elementos históricos 
que se apresentam como entrave para o reconhecimento do esporte e a profissionalização das atletas.

Em linhas gerais, vislumbramos que o campo em pesquisas sobre futsal e futebol feminino ainda está se consolidando, uma vez que ao considerarmos o recorte de cinco anos nos principais periódicos nacionais no campo da educação física, as publicações correspondem a um número relativamente baixo quando comparados a outros esportes.

Sugerimos, então, a necessidade de mais publicações no campo, para que possamos enxergar, de forma mais igualitária, o futebol nas amplas áreas de estudo que compreendem o campo da educação física. Aos periódicos, sugerimos que sejam desenvolvidos dossiês que contemplem está temática, com o intuito de incentivar as produções científicas

Cientes de que este estudo não esgota as discussões sobre as produções que envolvem o fenômeno do futebol/futsal feminino, sugerem-se que sejam desenvolvidos outros estudos de revisão com uma abordagem mais abrangente, contemplando os anais dos principais eventos do campo da Educação Física, bem como as teses e dissertações produzidaacerca de tal temática.

\section{REFERÊNCIAS}

BARREIRA, Júlia. Vantagem de jogar em casa no futebol feminino: uma análise dos três principais campeonatos no Brasil. Revista Brasileira de Ciências e Movimento,v. 26 n. 3. p. 83-87, 2018. Disponível em: https://portalrevistas.ucb.br/index.php/RBCM/article/view/7810. Acesso em 22 de maio 2020.

CHAN-VIANNA, Alexandre Jackson. J.; MOURA, Diego Luz. Futebol, mulheres e interação social. LICERE - Revista do Programa de Pós-graduação Interdisciplinar em Estudos do Lazer, v. 20, n. 4, p. 1-21, out./dez. 2017. Disponível em: https://periodicos.ufmg.br/index.php/licere/article/view/1722. Acesso em 20 de maio 2020.

CORRÊA, Lionela da Silva.; SILVA, Nívea Regina Sales da.; MASULLO, Romulo Vasconcelos. Futsal: a questão do gênero feminino na modalidade esportiva praticada em uma escola do ensino médio de Manaus-AM. Revista acta brasileira do movimento humano, v.5, n.3, p.1 - 9, jul./set. 2015. Disponível em: http://www.periodicos.ulbra.br/index.php/actabrasileira/article/view/2832. Acesso em 20 de maio 2020.

COSVOSKI, Thainara; ANTUNES, Mateus Dias.; OLIVEIRA, Daniel Vicentini de; FREIRE, Gabriel Lucas Morais; NASCIMENTO JÚNIOR, José Roberto Andrade do; ACENCIO, Fabio Ricardo. Síndrome de Burnout em atletas de futsal feminino universitárias: um estudo comparativo.Pensar a Prática, v. 22, n. 1, 29 nov. 2019. Disponível em: https://www.revistas.ufg.br/fef/article/view/55236. Acesso em 20 de maio 2020 .

FRANZINI, Fábio. Futebol é "coisa para macho"? Pequeno esboço para uma história das mulheres no país do futebol. Revista brasileira de história, São Paulo, v. 25, n. 50, jul./dez. 2005. Disponivel em: https://www.scielo.br/scielo.php?pid=s0102-01882005000200012\&script=sci arttext. Acesso em 20 de maio 2020 . 
GOELLNER, Silvana Vilodre. Mulheres e futebol no Brasil: entre sombras e visibilidades. Revista Brasileira de Educação Física e Esporte, v. 19, n. 2, p. 143-151, 2005. Disponível em: https://www.revistas.usp.br/rbefe/article/view/16590. Acesso em: 22 nov. 2020.

GUIRRA, Frederico Jorge Saad; ALMEIDA, Jacqueline Vieira. Análise da percepção de jogadores de futebol amador sobre mulheres que praticam o futebol. Pensar a Prática, v. 18, n. 3, 30 set. 2015. Disponível em: https://www.revistas.ufg.br/fef/article/view/34040. Acesso em 20 de maio 2020.

KASSIANO, Witalo; JESUS, Karla; ASSUMPÇÃO, Cláudio; LAMBOGLIA, Carminda.; MENDES, Alisson; BARBOSA, Ralciney; SABÓIA, Wilson.; SIMIM, Mário; MEDEIROS, Alexandre Igor Araripe. Respostas neuromusculares e fisiológicas durante o jogo em atletas de futsal feminino. Journal of Physical Education, v. 30, n. 1, p. e-3061, 2 jul. 2019. Disponível em: http://periodicos.uem.br/ojs/index.php/RevEducFis/article/view/43522. Acesso em 20 de maio 2020.

MARCONI, Marina de Andrade; LAKATOS, Eva Maria. Metodologia do trabalho científico:

procedimentos básicos, pesquisa bibliográfica, projeto e relatório, publicações e trabalhos científicos. 7. ed. 6. reimpr. São Paulo: Atlas: 2011.

MOREL, Marcia; SALLES, José Geraldo. Futebol Feminino. In: DACOSTA, Lamartine (Org.) Atlas do Esporte no Brasil. Rio de Janeiro: Confef, 2006.

MYSKIW, Mauro. Sociabilidades de mulheres na várzea: ensaio etnográfico acerca de relações de gêneros num circuito de futebol de Porto Alegre. Motrivivência, v. 28, n. 49, p. 114-127, nov. 2016. Disponível em: https://periodicos.ufsc.br/index.php/motrivivencia/article/view/2175-8042.2016v28n49p114. Acesso em: 27 de maio 2020.

PIRES, Renata Thober. Fatores motivacionais para a prática do futebol feminino em dois clubes profissionais na cidade de Porto Alegre. 2017. Trabalho de Conclusão de Curso - Graduação em Educação Física - Universidade Federal do Rio Grande do Sul, Porto Alegre-RS, 2017.

QUEIROGA, Marcos Roberto.; MEZALIRA, Francisco Moacir.; SOUZA, William Cordeiro de; WEBER, Vinicius Müller Reis.; CARVALHAES, Mayla Fernanda de Moura; FERREIRA, Sandra Aires; SILVA, Danilo Fernandes da. Perfil morfológico de atletas titulares e reservas de futsal feminino. Journal of Physical Education, v. 29, n. 1, p. e-2965, 23 set. 2018. Disponível em: http://periodicos.uem.br/ojs/index.php/RevEducFis/article/view/39992. Acesso em 27 de maio 2020.

SALVINI, Leila; MARCHI JÚNIOR, Wanderley. Registros do futebol feminino na revista Placar: 30 anos de história. Motrivivência, v. 28, n. 49, p. 99-113, nov. 2016. Disponível em:

https://periodicos.ufsc.br/index.php/motrivivencia/article/view/2175-8042.2016v28n49p99. Acesso em: 27 de maio 2020.

SOUZA, Ana Claudia Ferreira de; MARTINS, Mariana Zuaneti. O paradoxo da profissionalização do futsal feminino no Brasil: entre o esporte e outra carreira. Pensar a Prática, v. 21, n. 1, 29 mar. 2018. Disponível em: https://www.revistas.ufg.br/fef/article/view/45075. Acesso em: 27 de maio 2020.

SOUZA, Maria Thereza; CAPRARO, André; JENSEN, Larissa. Mulheres fora da área: escritoras "arriscando-se" a dissertar sobre futebol. Motrivivência, v. 29, n. 50, p. 140-152, abr. 2017. Disponível em: https://periodicos.ufsc.br/index.php/motrivivencia/article/view/2175-8042.2017v29n50p140. Acesso em: 27 de maio 2020.

SOUZA, Maria Thereza; CAPRARO, André; SILVA, Marcelo Moraes e. Habilidosas e bonitas: as considerações de duas atletas de futebol sobre a formação de suas identidades. Movimento, v. 23, n. 3, p. 883-894, jul./set. 2017. Disponível em: https://seer.ufrgs.br/Movimento/article/view/64827/43872. Acesso em: 27 maio 2020. 
TIESLER, Nina Clara. Three types of transnational players: differing women's football mobility projects in core and developing countries. Revista Brasileira deCiências do Esporte, Porto Alegre, v. 38, n. 2, p. 201-210, jun. 2016. Disponível em:

http://www.scielo.br/scielo.php?script=sci arttext\&pid=S0101-32892016000200201\&lng=pt\&nrm=iso.

Acesso em: 27 de maio 2020.

\section{NOTAS DE AUTOR}

AGRADECIMENTOS - Não se aplica.

CONTRIBUIÇÃO DE AUTORIA - Não se aplica.

FINANCIAMENTO - Recursos próprios.

CONSENTIMENTO DE USO DE IMAGEM - Não se aplica

APROVAÇÃO DE COMITÊ DE ÉTICA EM PESQUISA - Não se aplica.

CONFLITO DE INTERESSES - Não existem conflitos de interesse.

\section{LICENÇA DE USO}

Os autores cedem à Motrivivência- ISSN 2175-8042 os direitos exclusivos de primeira publicação, com o trabalho simultaneamente licenciado sob a Licenca Creative Commons Attribution Non-Comercial ShareAlike (CC BY-NC SA) 4.0 International. Esta licença permite que terceiros remixem, adaptem e criem a partir do trabalho publicado, desde que para fins não comerciais, atribuindo o devido crédito de autoria e publicação inicial neste periódico desde que adotem a mesma licença, compartilhar igual. Os autores têm autorização para assumir contratos adicionais separadamente, para distribuição não exclusiva da versão do trabalho publicada neste periódico (ex.: publicar em repositório institucional, em site pessoal, publicar uma tradução, ou como capítulo de livro), com reconhecimento de autoria e publicação inicial neste periódico, desde que para fins não comerciais e compartilhar com a mesma licença.

\section{PUBLISHER}

Universidade Federal de Santa Catarina. Programa de Pós-Graduação em Educação Física. LaboMídia - Laboratório e Observatório da Mídia Esportiva. Publicado no Portal de Periódicos UFSC. As ideias expressadas neste artigo são de responsabilidade de seus autores, não representando, necessariamente, a opinião dos editores ou da universidade.

\section{EDITORES}

Mauricio Roberto da Silva, Giovani de Lorenzi Pires, Rogério Santos Pereira.

\section{EDITOR DE SEÇÃO}

Rafael Matiuda Spinelli.

\section{REVISÃO DO MANUSCRITO E METADADOS}

João Caetano Prates Rocha; Keli Barreto.

\section{HISTÓRICO}

Recebido em: 05 de agosto de 2020.

Aprovado em: 28 de janeiro de 2021. 